
for

\author{
RUTHERFORD \\ BACKSCATTERING \\ ANALYSIS OF THE FAILURE \\ OF CHLORINE ANODES
}

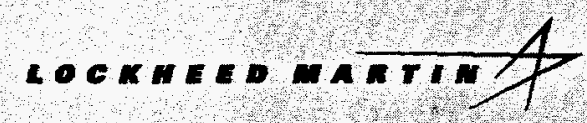

C. E. Vallet

Oak Ridge National Laboratory

B. V. Tilak

Occidental Chemical Corporation 
This report has been reproduced directly from the best available copy.

Available to DOE and DOE contractors from the Office of Scientific and Technical Information, P. O. Box 62, Oak Ridge, TN 37831; prices available from (423) 576-8401, FTS 626-8401.

Available to the public from the National Technical Information Service, U.S. Department of Commerce, 5285 Port Royal Road, Springfield. VA 22161.

This report was prepared as an account of work sponsored by an agency of the United States Government. Neither the United States Government nor any agency thereof, nor any of their employees, makes any warranty, express or implied, or assumes any legal liability or responsibility for the accuracy, completeness, or usefulness of any information, apparatus, product, or process disclosed, or represents that its use would not infringe privately owned rights. Reference herein to any specific commercial product, process, or service by trade name, trademark, manufacturer, or otherwise, does not necessarily constitute or imply its endorsement, recommendation, or favoring by the United States Government or any agency thereof. The views and opinions of authors expressed herein do not necessarily state or reflect those of the United States Government of any agency thereof. 


\section{DISCLAIMER}

Portions of this document may be illegible in electronic image products. Images are produced from the best available original document. 
Chemical and Analytical Sciences Division

\title{
RUTHERFORD BACKSCATTERING ANALYSIS OF THE FAILURE OF CHLORINE ANODES
}

\author{
CRADA Final Report \\ for \\ CRADA Number ORNL95-0331
}

C. E. Vallet

Oak Ridge National Laboratory

B. V. Tilak

Occidental Chemical Corporation

Date Published: June 1, 1996

ORNL/M-5209

OAK RIDGE NATIONAL LABORATORY

Oak Ridge, Tennessee 37831-6197

managed by

LOCKHEED MARTIN ENERGY RESEARCH CORPORATION for the

U.S. DEPARTMENT OF ENERGY

under contract DE-AC05-96OR22464 


\section{TABLE OF CONTENTS}

$\begin{array}{ll}\text { ABSTRACT } & 1\end{array}$

STATEMENT OF THE OBJECTIVES OF THE CRADA

SUCCESS IN MEETING THE OBJECTIVES 2

BENEFITS TO DOE MATERIALS SCIENCES PROGRAM 2

TECHNICAL REPORT

EXPERIMENTAL

Preparation Procedure 4

Rutherford Backscattering 5

A.C. Impedance Measurements 6

$\begin{array}{ll}\text { RESULTS } & 6\end{array}$

As-prepared Electrodes

$\begin{array}{ll}\text { Used Anodes } & 10\end{array}$

$\begin{array}{ll}\text { SUMMARY } & 14\end{array}$

$\begin{array}{ll}\text { REFERENCES } & 14\end{array}$

$\begin{array}{ll}\text { INVENTIONS } & 16\end{array}$

COMMERCIALIZATION POSSIBILITIES 16

PLANS FOR FUTURE COLLABORATION 16

$\begin{array}{ll}\text { CONCLUSIONS } & 16\end{array}$

$\begin{array}{ll}\text { DISTRIBUTION LIST } & 17\end{array}$ 


\begin{abstract}
Rutherford Backscattering Spectrometry, carried out at the ORNL Surface Modification And Characterization Collaborative Research Center (SMAC) facility, has been applied to the nondestructive analysis of $\mathrm{RuO}_{2}-\mathrm{TiO}_{2}$ electrodes of $5000 \AA$, which mimic the DSA anodes in composition and the method of preparation. Occidental Chemical Corporation provided electrodes, which had been subjected to life time testing in $\mathrm{H}_{2} \mathrm{SO}_{4}$ solution, for analysis by ORNL. The results were used to test the hypothesis of degradation of theses, and similar electrodes, from a process involving a decrease in the $\mathrm{RuO}_{2}: \mathrm{TiO}_{2}$ ratio at and near the electrode surface and the related decrease in the electrode electrical conductivity. The drop in electrode activity is closely linked to a decrease in $\mathrm{Ru}$ content, and the measured profiles show that the loss takes place across the thin $\mathrm{RuO}_{2}-\mathrm{TiO}_{2}$ coating. No build up of a pure $\mathrm{TiO}_{2}$ layer is apparent. The data agree quantitatively with the critical concentration previously reported by ORNL for materials produced by ion implantation and characterized by Rutherford Backscattering Spectrometry and Photoacoustic Spectrometry. The study has brought a better understanding of the degradation process in electrodes of great technological importance, and has given a more solid background in designing new fabrication procedures for improved electrodes.
\end{abstract}

\title{
STATEMENT OF THE OBJECTIVES OF THE CRADA
}

The purpose of the CRADA NO 95-0331 between Lockheed Martin Energy Research Corporation and Occidental Chemical Corporation was to obtain insights into the mechanisms of wear and passivation of $\mathrm{RuO}_{2}-\mathrm{TiO}_{2}$ anodes similar to that used in chlorine/caustic soda production.

The lifetime of anodes, typically fabricated by application of successive coatings of ruthenium and titanium salt mixtures on titanium substrate and oxidation in air at high temperature, depends on the method of preparation, the operating voltage, and the electrolyte brine composition. The mechanisms of failure are still unclear. Failure of the anode may correlate with a loss of $\mathrm{RuO}_{2}$ at the surface and also is suspected to be related to the formation of a nonconductive $\mathrm{TiO}_{2}$ layer. The gradual build up of $\mathrm{TiO}_{2}$ could explain the observed increase in electrode overpotential and the consequent loss in efficiency of the process. The purpose of the collaboration was to test the hypothesis of failure due to changes in electrode composition by nondestructively characterizing the surface of electrodes at different times of use, and therefore with performance ranging from good to that of a failed anode.

The objectives of the two parties involved in the project were as follows: 
- For Occidental Chemical Corporation, to provide ORNL with electrodes similar to that used in chlorine production, but with thickness compatible to Rutherford Backscattering depth profiling, i.e., much thinner than the electrodes actually used;

- For Occidental Chemical Corporation, to send these electrodes to ORNL for analysis with documented results of life tests and electrochemical measurements of impedance and potentiodynamic analysis in relevant chloride solution;

- For ORNL to analyze the electrode superficial layers over a typical thickness of a few thousand Angstroms by Rutherford Backscattering Spectrometry;

- For ORNL to use and develop a suitable method of numerical analysis of the resulting RBS spectra in order to provide quantitative results of the composition changes as well as the location, within the electrode, at which the composition changes occur;

- For ORNL to prepare manuscript and the final report.

\section{SUCCESS IN MEETING THE OBJECTIVES}

Occidental Chemical participant has provided ORNL with samples amenable to measurements by Rutherford backscattering spectrometry on a timely manner. Adjustments in the thickness were made as required from the ORNL contractor. The ORNL contractor was able to deliver analytical results of these samples in the time frame established in the CRADA agreement.

Partial results have been presented at the 18 th DOE Surface Science Conference, Oak Ridge, TN, May 10-11, 1995 and at the Electrochemical Society Spring Meeting, Reno, NV May 21-26, 1995. A paper, which is in the clearance process, has been prepared for submission to the Journal of the Electrochemical Society.

\section{BENEFITS TO DOE MATERIALS SCIENCES PROGRAM}

The Office of Basic Energy Sciences-Materials Sciences Program has funded an electrocatalysis project for a number of years. ORNL has a number of publications in the literature on the fundamentals of the mechanism of chlorine evolution at Ti/Ru oxide electrodes and has been invited over the years to give papers at international topical meetings such as "Progress in Electrocatalysis: Theory and Practice," Ferrara, Italy (1993). ORNL was solicited by the participant to collaborate in this project because of publications in the open literature 
dealing with Rutherford Backscattering Spectrometry used on ion-implanted Ti/Ru model electrodes. ORNL experience, expertise and Surface Modification And Characterization facility (SMAC) were keys to make the collaboration with Chemical Occidental Corp. possible and successful. The focus of ORNL contribution to this project was the characterization of materials with the electrochemistry done entirely by the Occidental Chemical participant. The production of chlor-alkali commodity chemicals is of major importance to the U.S. chemical industry here and abroad particularly in the Pacific region. Improvement to electrode materials could increase efficiency and prolong the life of the electrodes, thus lowering the costs of production. ORNL has unique experience in the fabrication and characterization of model electrodes and applying this experience to "real world" production electrodes substantiates the model and may lead to new procedures for building improved electrodes.

\section{TECHNICAL REPORT}

Anodes of the chlorine reaction are typically mixed oxides of $\mathrm{Ru}, \mathrm{Ir}, \mathrm{Ta}, \mathrm{Sn}$ and titanium. Ruthenium oxide must be present in large quantity because it is the most efficient catalyst, but other oxides are needed for the stability of the electrode. The most widely used anodes in the chlor-alkali industry are the $\mathrm{RuO}_{2}-\mathrm{TiO}_{2}$ coated titanium electrodes ${ }^{1}$, commonly referred to in the industry as DSA (dimensionally stable anode) electrodes ${ }^{2,3}$. These electrodes have a long life and operate at a low chlorine overpotential and at a high efficiency. However, upon prolonged use, deactivation of these anodes occurs resulting in high chlorine overvoltages. The loss of anode activity appears to be related to the loss of $\mathrm{RuO}_{2}$ from the coating which may lead to the formation of a poorly conducting $\left(\mathrm{TiO}_{2}\right.$-rich) oxide or of an insulating $\mathrm{TiO}_{2}$ layer.

The purpose of this study is to characterize and locate these non-conducting entities in the coating in order to design new preparation procedures for improved electrodes. Because of the technological importance of the reaction, many electrochemical investigations were made and mechanisms were proposed ${ }^{4}$ based on observations of effects from various factors related to the electrolyte and the electrode surface such as preparation method, catalyst concentration, surface porosity, etc. However, the most sophisticated electrochemical measurements only can give the overall result of complex mechanisms occuring concurrently and on various time scales at the electrode/solution interface. The electrochemical measurements usually are analyzed in terms of an infinitely thin smooth surface which defines the electrode/solution interface. In reality, the mixed oxide anodes are porous, and the electrochemical reaction occurs ${ }^{5}$ at different depths in the porous structure. There is a need for probing the electrode surface by alternative methods sensitive to the chemistry and to the structure of the surface.

Recent progresses in the understanding of anodes performance have been made by concurrent use of various techniques, probing different depths, and/or amenable to depth profiling. Electrode surfaces, "as produced", have been observed ${ }^{6}$ by SEM/EDX to assess their porosity and the catalyst distribution at the surface. These investigations showed a cracked-mud structure with cracks deep enough to uncover the titanium support. The EDX mapping of elements gave only a quantitative overview of the local composition at the surface. It should be noted that EDX may probe the material too deep to be relevant to the electrochemical process. 
Therefore, the relation between an EDX mapping and the performance of an electrode may not be staightforward in terms of number of active catalytic species displayed. The XPS technique has been the most used $\mathrm{d}^{7-14}$ because of its chemical specifity and of its potential for depth profiling. However, XPS analysis is difficult for ruthenium, a key element in chlorine anodes, because of overlapping of the ruthenium and carbon peaks. On the other hand, caution must be exercised with results from depth profiling analysis because the argon sputtering beam reacts with the surface, notably by reducing titanium oxide ${ }^{9}$. Improved results can be expected from this technique with angle resolved measurements and with systems sensitive enough to rely on a secondary ruthenium peak. Auger spectroscopy has been used ${ }^{11,14}$ to analyze the surface of DSA-like anodes. The method has the advantage of probing a small volume under the surface, but can not deliver a chemical analysis. Problems with the overlapping of the ruthenium and carbon peaks have been resolved by considering the symmetry of the peaks and by reducing the size of the electron beam ${ }^{15}$. Scanning Auger Spectroscopy with a microprobe $(0.6 \mu \mathrm{m})^{15}$ has recently produced images of $\mathrm{RuO}_{2}-\mathrm{TiO}_{2}$ anodes which could be related with the topography of SEM images and which were much sharper than EDX elemental mappings. Segregation of $\mathrm{RuO}_{2}$ was studied by this method. Rutherford Backscattering Spectrometry (RBS) has the advantage to allow a non-destructive and accurate depth profiling over a few thousand Angstroms. The method is widely used in studies of layered structures, but rarely in the characterization of mixed oxide anode materials. The experimental spectra can be simulated ${ }^{16}$ by using the stopping powers and ranges of helium in different elements ${ }^{17}$, and consequently there is no need for preparing standards of known compositions. The recent application of $\mathrm{RBS}^{18}$ to a $\mathrm{SnO}_{2}-\mathrm{IrO}_{2}$ coating gave compositions sustained by analysis by inductively coupled plasma emission spectroscopy (ICPES).

In this study, thin film electrodes, which mimic the DSA anodes in composition and preparation method, have been prepared, tested for their activity toward the chlorine evolution reaction, and subjected to life time testing in sulfuric acid solution. Electrochemical data, taken at different times during electrolysis, including for an electrode after failure, will be presented and compared to depth profiling analyses of the mixed oxide anode by Rutherford Backscattering Spectrometry (RBS).

\section{EXPERIMENTAL}

\section{Preparation Procedure}

Samples with an oxide layer thickness of a few thousands Angstroms were made on titanium plates. The preparation procedure includes all the steps used for industrial DSA anodes, but was modified in order to produce thinner mixed oxide layers amenable to characterization by RBS. The titanium plate surface first was carefully cleaned by a combination of sand blasting with $\mathrm{SiC}$, immersion in trichloroethylene, etching by a $10 \%$ oxalic acid $+18 \% \mathrm{HCl}$ mixture at $90^{\circ} \mathrm{C}$ and rinsing with water and methanol. Dilute solutions of $\mathrm{RuCl}_{3}$ and $\mathrm{TiCl}_{3}$ in ethanol (with 40:60 wt\% Ru:Ti) were used to coat the surface. After each coating the samples were fired at $430-450^{\circ} \mathrm{C}$. Two sets of electrodes were produced with different dilutions of the chloride solution and different numbers of coatings. They were 
intended to provide guidelines for controlling the thickness of resulting oxide layers. These electrodes have been analyzed by X-ray fluorescence (XRF) to estimate the Ru concentration (in $\mathrm{Ru} \mathrm{g} \mathrm{m}{ }^{-2}$ ). One of these electrodes has been submitted to accelerated life tests in a $0.5 \mathrm{M} \mathrm{H}_{2} \mathrm{SO}_{4}$ solution at a constant anodic current of $0.5 \mathrm{~A} \mathrm{~cm}^{-2}$ at $25^{\circ} \mathrm{C}$. Samples, removed at different times during the electrolysis, were analyzed by Rutherford Backscattering Spectrometry and subjected to electrochemical tests in an effort to correlate the composition changes in the oxide with the observed increase in the cell voltage. Table I lists the electrodes, for which RBS and impedance results will be discussed, together with the preparative procedure and other available characterization data.

TABLE I : Summary of preparation procedures and available characterization data of the $\mathrm{RuO}_{2}$ $\mathrm{TiO}_{2} / \mathrm{Ti}$ thin film electrodes studied by RBS and A.C. impedance measurements.

\begin{tabular}{|c|c|c|c|c|c|}
\hline $\begin{array}{c}\text { Electrode } \\
\#\end{array}$ & $\begin{array}{l}\text { Solution } \\
\text { Dilution }\end{array}$ & $\begin{array}{l}\text { Number of } \\
\text { Coatings }\end{array}$ & $\begin{array}{c}\text { XRF } \\
\text { Ru g } \mathbf{m}^{-2}\end{array}$ & $\begin{array}{c}\text { Cell* } \\
\text { Voltage/V }\end{array}$ & $\begin{array}{l}\text { Electrolysis } \\
\text { Time/minute }\end{array}$ \\
\hline $10-4$ & 1:10 & 4 & .58 & $\mathrm{NA}$ & $\mathbf{N A}$ \\
\hline $10-5$ & 1:10 & 5 & .77 & NA & $\mathbf{N A}$ \\
\hline $10-6$ & 1:10 & 6 & .73 & NA & NA \\
\hline $5-1$ & $1: 5$ & 1 & .58 & NA & NA \\
\hline $5-3$ & $1: 5$ & 3 & .81 & NA & NA \\
\hline 5-5 & 1:5 & 5 & 1.44 & NA & NA \\
\hline 1 & $1: 5$ & 3 & .81 & NA & 0 \\
\hline 2 & 1:5 & 3 & NA & 3.2 & 10 \\
\hline 3 & 1:5 & 3 & NA & 3.3 & 25 \\
\hline 4 & 1:5 & 3 & NA & 3.5 & 45 \\
\hline 5 & 1:5 & 3 & NA & 4.4 & 65 \\
\hline 6 & 1:5 & 3 & NA & 3.0 & 77 \\
\hline
\end{tabular}

${ }^{*}$ Cell voltage at time of removal after electrolysis at constant current of $0.5 \mathrm{~A} \mathrm{~cm}{ }^{.2}$ in $0.5 \mathrm{M}$ $\mathrm{H}_{2} \mathrm{SO}_{4}$ at $25^{\circ} \mathrm{C}$ during times indicated in the next column.

\section{Rutherford Backscattering Spectrometry}

The Rutherford Backscattering Spectrometry (RBS) technique can probe ${ }^{16}$ depths of several thousands Angstroms in a solid by analyzing the energy of a high energy ${ }^{4} \mathrm{He}$ beam after its interaction with this solid. The results include the analysis of as-prepared electrodes produced with different procedures, the comparison of RBS estimated Ru loadings to loadings measured by XRF and, the analysis of Ru content in one anode at different times of galvanostatic use.

The Rutherford Backscattering experiments were done with a $2 \mathrm{MeV}^{4} \mathrm{He}$ beam impinging normally on the electrode surface and an energy sensitive collector placed in such a way that the scattering angle is fixed at $160^{\circ}$. The detector has an energy resolution on the order of $20 \mathrm{keV}$ and a solid angle of 2-3 degrees. In this configuration, the $2 \mathrm{MeV}$ beam, after colliding (elastic 
collision) with a Ru atom at the surface, typically is detected at an energy of $1.715 \mathrm{MeV}$. The elastic energy loss decreases with increasing atomic mass and the energy scale can be converted readily into an atomic mass scale for the scattering surface atoms. In reality, the experimental spectra are more difficult to interpret because the ${ }^{4} \mathrm{He}$ beam penetrates inside the solid and collides with atoms situated at various distances from the surface. The energetic ${ }^{4} \mathrm{He}$ beam, during its travel in the sample, is slowed down by electronic forces, and consequently the backscattered beam is observed with a variety of energies lower

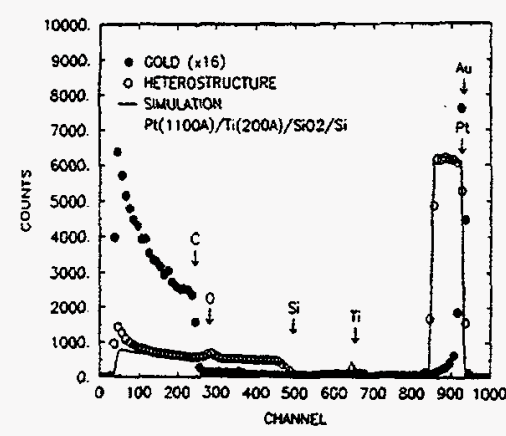

Figure 1 Rutherford Backscattering Spectra obtained with a $2 \mathrm{MeV}^{4} \mathrm{He}$ beam and $160^{\circ}$ scattering angle: gold monolayer on graphite; $\mathrm{Pt} / \mathrm{Ti} / \mathrm{SiO}_{2} / \mathrm{Si}$ thin film heterostructure; simulation. Arrows show energies for indicated surface atoms. than that corresponding to a surface atom. In fact, the resulting spectra consist of peaks with width and shape reflecting the concentration of scattering atoms below the surface as well as at the surface. The interaction of the beam with a solid can be reasonably well calculated near the surface, but the calculations become less accurate as the beam is slowed down. Practically, the calculation is good over about 1000 to $2000 \AA$. Figure 1 illustrates this fact by comparing the spectra obtained for a nearmonolayer film of gold deposited on carbon and for a heterostructure including a $1000 \AA$ thick platinum film on top of a $200 \AA$ thick titanium film. The gold monolayer peak is very sharp with a leading edge reflecting the energy resolution of the detector. The edge at channel 200 is due to the carbon substrate. The complex spectrum of the heterostructure, with a Pt peak of about 50 channel half height width, is successfully simulated by taking thicknesses of $1100 \AA$ and $200 \AA$ for the Pt and Ti upper layers, respectively. However, it should be pointed out that the agreement is not as good in the simulation of the $\mathrm{SiO}_{2} / \mathrm{Si}$ substrate interface. The simulation gives a thickness of $2700 \AA$ for $\mathrm{SiO}_{2}$ instead of the presumed value of $1000 \AA$. The discrepancy may be attributable to the location of the layer, (at more than $1000 \AA$ below the surface), and to the fact that the analyzed layer is an oxide with more complex interactions with the probing beam than an elemental metal.

\section{A.C. Impedance Measurements}

The measurements were performed in $0.5 \mathrm{M} \mathrm{H}_{2} \mathrm{SO}_{4}$ solutions with a EG \& G Model 273 potenstiostat/galvanostat and a Model 5210 lock-in amplifier. The frequency range employed was from $100 \mathrm{kHz}$ to $1 \mathrm{mHz}$ with a sine wave amplitude of $5 \mathrm{mV}$.

\section{RESULTS}

As-prepared Electrodes 
Figure 2 shows RBS data obtained for electrode \#5-3 (fabricated with a 1:5 dilution of

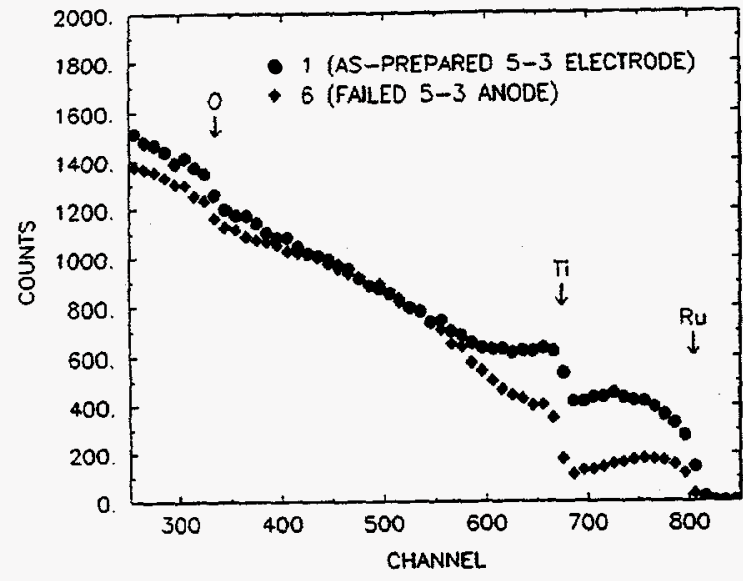

Figure $2 \mathrm{RBS}$ spectra obtained with a $2 \mathrm{MeV}$ ${ }^{4} \mathrm{He}$ beam and $160^{\circ}$ scattering angle: $\bullet$ as prepared \#5-3 electrode; failed (after electrolysis) \#5-3 anode. Arrows show energies for indicated surface atoms.

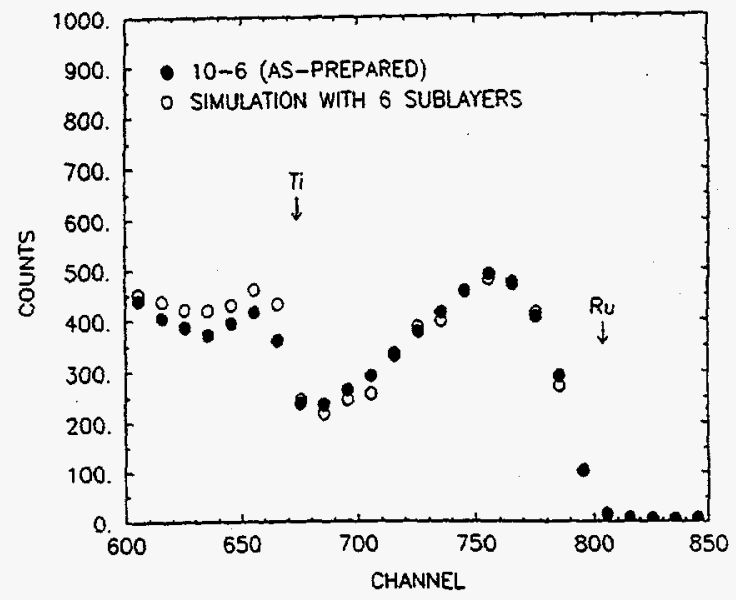

Figure 3 Experimental $(\bullet)$ and calculated $\left({ }^{\circ}\right)$ RBS leading edges of $\mathrm{Ru}$ and $\mathrm{Ti}$ for electrode \#10-6. Arrows show energies for indicated surface atoms.

the solution and with three coats) before use and after electrochemical use up to failure of the electrode. Qualitatively, by comparing the heights of the Ru peaks, it is clear that the as-prepared electrode contains a larger quantity of ruthenium than the failed electrode. The positions of the edges of $R u$ and of Ti peaks show clearly that $\mathrm{Ru}$ and $\mathrm{Ti}$ are present at the surface. The oxygen peak appears over a too large background to be of any analytical use. Finally, it should be noted that the samples examined are still thick for the RBS technique.

In order to reproduce fairly well the experimental spectra, the oxide layer had to be arbitrarily cut in portions of different $\mathrm{Ru}$ : Ti ratios. Typically the Ru concentration peaks are near or at the surface, and the Ru concentration is the lowest at the Ti substrate interface. Figure 3 shows the experimental and simulated spectra for the as-prepared electrode \#10-6. The fit has been obtained by representing the mixed oxide layer with 6 sublayers of different Ru:Ti ratios. The layers are described in the calculations by their fluence in atom $\mathrm{cm}^{-2}$ and compositions in atom fraction of $\mathrm{Ru}, \mathrm{Ti}$ and $\mathrm{O}$. The thickness, $d$, of a sublayer is calculated by

$$
d l c m=\frac{F}{N_{A v}}\left\{a t(R u) x \frac{M_{R_{u} O_{2}}}{\rho_{R u O_{2}}}+a t(T i) x \frac{M_{T_{i} O_{2}}}{\rho_{T i O_{2}}}\right\}
$$

Where at $(i)$ is the concentration of $i$ atom in atom fraction; $F$ is the fluence in at $\mathrm{cm}^{-2} ; N_{A v}$ is the Avogadro's number; $M_{\mathrm{RuO}_{2}}$ and $M_{\mathrm{TiO}_{2}}$ are the molecular weights of $\mathrm{RuO}_{2}$ and $\mathrm{TiO}_{2}$, respectively; $\rho_{\mathrm{RuO}}=6.97 \mathrm{~g} \mathrm{~cm}^{-3}$ and $\rho_{T i O_{2}}=3.84 \mathrm{~g} \mathrm{~cm}^{-3}$ are the densities of $\mathrm{RuO}_{2}$ and $\mathrm{TiO}_{2}$, respectively.

The concentration of $\mathrm{Ru}$ in each sublayer, $C_{R u}$ is calculated with 


$$
C_{R u} \text { lat } \mathrm{cm}^{-3}=\frac{a t(R u) x F}{d}
$$

The simulations of spectra for all the electrodes give total oxide thicknesses in the 3000 to $6000 \AA$ range. Since XRF measurements probe depths on the order of microns, the $\mathrm{Ru}$ loadings measured by XRF are compared with the sum of $\mathrm{Ru}$ contents over all the sublayers included in the simulations. Equation (3) is used to calculate the electrode ruthenium loading, $C L_{R u}$

$$
C L_{R u} / R u g m^{-2}=10^{4} \times \frac{M_{R u}}{N_{A v}} \sum_{i=1, n} F_{i} \times a t(R u)_{i}
$$

Where $M_{R u}$ is the atomic weight of $R u ; n$ is the number of layers in the simulation; $F_{i}$ and $a t(R u)_{i}$ are the fluence in at $\mathrm{cm}^{-2}$ and the concentration of $\mathrm{Ru}$ atom in the ith layer, respectively.

Table II summarizes the results of the simulation of RBS spectra for electrodes prepared from the $1: 5$ and $1: 10$ solutions. In these calculations, 3 to 6 sublayers have been included. The

\begin{tabular}{|c|c|c|c|c|c|c|}
\hline Electrode & $5-1$ & $5-3$ & $5-5$ & $10-4$ & $10-5$ & $10-6$ \\
\hline $\begin{array}{l}\text { Numbers of Layers, } \\
\text { n }\end{array}$ & 6 & 6 & 3 & 4 & 4 & 6 \\
\hline $\begin{array}{l}\text { Layer } 1 \\
\left.\text { Fiuence (at } \mathrm{cm}^{2}\right) \\
\text { Ru(atom fraction) } \\
C_{\text {Ru }}\left(\text { at } \mathrm{cm}^{3}\right)\end{array}$ & $\begin{array}{c}1 \times 10^{17} \\
0.045 \\
4.0 \times 10^{31}\end{array}$ & $\begin{array}{c}2.8 \times 10^{17} \\
0.07 \\
6.2 \times 10^{21}\end{array}$ & $\begin{array}{c}4.4 \times 10^{12} \\
0.05 \\
4.4 \times 10^{22}\end{array}$ & $\begin{array}{c}6.0 \times 10^{19} \\
0.11 \\
9.8 \times 10^{21}\end{array}$ & $\begin{array}{c}2.0 \times 10^{17} \\
0.025 \\
2.2 \times 10^{\text {21 }}\end{array}$ & $\begin{array}{c}2.0 \times 10^{19} \\
0.03 \\
2.6 \times 10^{21}\end{array}$ \\
\hline $\begin{array}{l}\text { Layer } 2 \\
\text { Fluence (at } \mathrm{cm}^{-2} \text { ) } \\
\text { Ru(atom fraction) } \\
\left.C_{\text {g }} \text { (at } \mathrm{cm}^{-1}\right)\end{array}$ & $\begin{array}{c}7.0 \times 10^{13} \\
0.055 \\
4.8 \times 10^{21} \\
\end{array}$ & $\begin{array}{c}2.0 \times 10^{17} \\
0.08 \\
7.1 \times 10^{212} \\
\end{array}$ & $\begin{array}{c}2.0 \times 10^{1 \mathrm{x}} \\
0.1 \\
8.9 \times 10^{21} \\
\end{array}$ & $\begin{array}{c}5.0 \times 10^{27} \\
0.07 \\
6.2 \times 10^{13} \\
\end{array}$ & $\begin{array}{c}9.0 \times 10^{17} \\
0.09 \\
8.0 \times 10^{12} \\
\end{array}$ & $\begin{array}{c}2.7 \times 10^{17} \\
0.09 \\
8.0 \times 10^{31}\end{array}$ \\
\hline $\begin{array}{l}\text { Layer } 3 \\
\left.\text { Fluence (at } \mathrm{cm}^{-2}\right) \\
\text { Ru(atom fraction) } \\
C_{\ln }\left(2 \mathrm{~cm} \mathrm{~cm}^{3}\right) \\
\end{array}$ & $\begin{array}{c}4.0 \times 10^{17} \\
0.05 \\
4.4 \times 10^{42} \\
\end{array}$ & $\begin{array}{c}3.0 \times 10^{13} \\
0.085 \\
7.5 \times 10^{21} \\
\end{array}$ & $\begin{array}{c}2.5 \times 10^{14} \\
0.07 \\
6.2 \times 10^{13} \\
\end{array}$ & $\begin{array}{c}4.0 \times 10^{17} \\
0.05 \\
4.4 \times 10^{21} \\
\end{array}$ & $\begin{array}{c}7.0 \times 10^{17} \\
0.07 \\
6.2 \times 10^{91} \\
\end{array}$ & $\begin{array}{c}7.0 \times 10^{17} \\
0.115 \\
1.0 \times 10^{13}\end{array}$ \\
\hline $\begin{array}{l}\text { Layer } 4 \\
\left.\text { Fluence (at } \mathrm{cm}^{-2}\right) \\
\text { Ru(atom fraction) } \\
C_{R_{-}}\left(\text {at } \mathrm{cm}^{2}\right) \\
\end{array}$ & $\begin{array}{c}4.0 \times 10^{17} \\
0.04 \\
3.5 \times 10^{21} \\
\end{array}$ & $\begin{array}{c}6.0 \times 10^{17} \\
0.1 \\
8.9 \times 10^{22} \\
\end{array}$ & & $\begin{array}{c}1.2 \times 10^{111} \\
0.015 \\
1.3 \times 10^{28} \\
\end{array}$ & $\begin{array}{c}9.0 \times 10^{17} \\
0.04 \\
3.5 \times 10^{21}\end{array}$ & $\begin{array}{c}6.0 \times 10^{17} \\
0.09 \\
8.0 \times 10^{2}\end{array}$ \\
\hline $\begin{array}{l}\text { Layer } 5 \\
\left.\text { Fluence (at } \mathrm{cm}^{-2}\right) \\
\text { Ru(atom fraction) } \\
C_{\text {en }}\left(\mathrm{at} \mathrm{cm}^{3}\right) \\
\end{array}$ & $\begin{array}{c}6.0 \times 10^{17} \\
0.035 \\
3.1 \times 10^{21} \\
\end{array}$ & $\begin{array}{c}5.0 \times 10^{17} \\
0.09 \\
8.0 \times 10^{23} \\
\end{array}$ & & & & $\begin{array}{c}6.0 \times 10^{17} \\
0.055 \\
4.8 \times 10^{21} \\
\end{array}$ \\
\hline $\begin{array}{l}\text { Layer } 6 \\
\text { Fuence (at } \mathrm{cm}^{-2} \text { ) } \\
\text { Ru(atom fraction) } \\
C_{\text {R. }}\left(2 t \mathrm{~cm}^{-1}\right) \\
\end{array}$ & $\begin{array}{c}8.0 \times 10^{17} \\
0.025 \\
2.2 \times 10^{22} \\
\end{array}$ & $\begin{array}{c}2.7 \times 10^{1 *} \\
0.07 \\
6.2 \times 10^{21} \\
\end{array}$ & : & & & $\begin{array}{c}2.0 \times 10^{38} \\
0.04 \\
3.5 \times 10^{13} \\
\end{array}$ \\
\hline Thickness $(\dot{A})$ & 3420 & 5200 & 5610 & 3100 & 3100 & 5050 \\
\hline$C L_{R u}\left(\mathrm{Ru} \mathrm{g} \mathrm{m}^{-2}\right)$ & 0.23 & 0.60 & 0.67 & 0.27 & 0.29 & 0.42 \\
\hline
\end{tabular}

TABLE II: RBS analysis of as-prepared $\mathrm{RuO}_{2}-\mathrm{TiO}_{2} / \mathrm{Ti}$ thin film electrodes. 


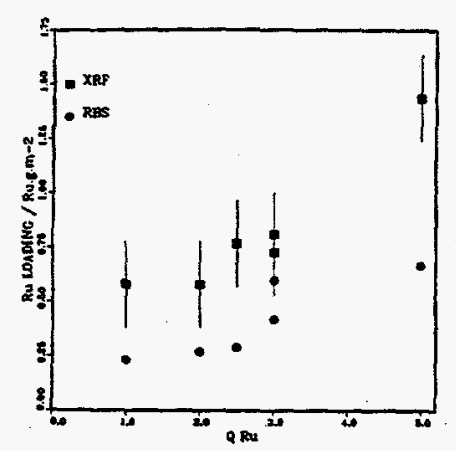

Figure 4 Ruthenium loadings of two sets of electrodes : $\bullet$ measured by RBS; measured by XRF. sensitivity of the simulation to the number of assumed sublayers has been tested by comparing results obtained with two and six sublayers on the \#5-3 electrode. The simulation with two sublayers gives a thickness of $5065 \AA$ instead of $5200 \AA$ with six sublayers and a ruthenium loading, $C L_{R 2}$ of $0.72 \mathrm{Ru} \mathrm{g} \mathrm{m}^{-2}$ instead of $0.60 \mathrm{Ru} \mathrm{g}$ $\mathrm{m}^{-2}$ with six sublayers. The discrepancy is on the order of magnitude of the uncertainty of $0.2 \mathrm{Ru} \mathrm{g} \mathrm{m}^{-2}$ generally reported for XRF analysis. The concentrations of Ru assumed in the sublayers vary from 0.015 to 0.115 atom fraction. Except for the electrode prepared with one coat, \#5-1, the simulation includes one or more sublayers with a composition of 0.08 atom fraction of $\mathrm{Ru}$ or higher. The latter value corresponds to the composition in the precursor solution. Thus, the RBS simulation appears to provide very reasonable values for the $\mathrm{Ru}$ content in the mixed oxide film. The local fluctuations of composition around the precursor solution composition may be attributable to loss and to diffusion during the application of successive layers. These first results suggest that RBS could be used for optimizing the preparation procedure by monitoring the build up of the mixed oxide layer. However, the $C L_{R u}$ values derived with Equation (3) are consistently smaller than those measured by XRF and reported in column 4 of Table I. Both sets of data are plotted versus the quantity of Ru coated on the Ti substrate, $\mathrm{Q}_{\mathrm{R} u}$, in Figure 4. $\mathrm{Q}_{\mathrm{Ru}}$, is expressed in units corresponding to the $\mathrm{Ru}$ content of one coat

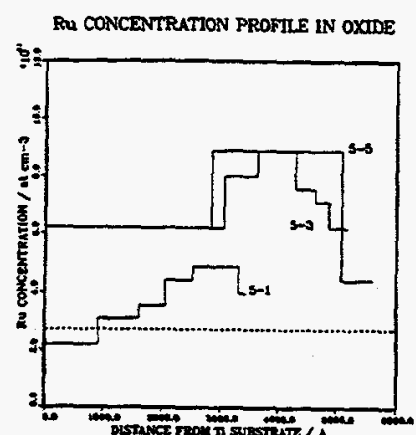

Figure 5 RBS data for dashed line is discussed with Fig.7. \#5-1,5-3 \& 5-5. The of $1: 5$ solution on one $\mathrm{cm}^{2}$ surface unit. In these units, the quantity of $\mathrm{Ru}$ applied by four coatings with 1:10 solution is 2 . The values obtained by the two methods appear to fall on different lines, which may suggest a systematic error. Since the standards used in the XRF measurements have not been examined by RBS, and were outside the range of values used here, the discrepancy may come from incorrect extrapolation. The large difference in masses between $\mathrm{Ru}$ and $\mathrm{Ti}$ matrix atoms may increase the uncertainty of a linear extrapolation ${ }^{19}$.

The distribution of $\mathrm{Ru}$ within the oxide layer is shown in Figure 5 for electrodes \#5-1, \#5-3 and \#5-5. The general shape of the profiles is not largely altered by the choice of taking only three layers in the simulation of \#5-5. The most superficial layer in the three simulations appears to be slightly depleted in ruthenium. It cannot be ruled out that this result is an artifact stemming from the fitting of the spectra sloping leading edge attributable to surface roughness and to the detector resolution. The comparison of profiles in \#5-1 and in \#5-3 suggests that diffusion of $\mathrm{Ru}$ toward the substrate may take place during successive preparation steps. This would explain the non-uniform concentration of $\mathrm{Ru}$ in the oxide and the build up of $\mathrm{Ru}$ at the $\mathrm{Ti}$ substrate surface from one coating $\left(2 \times 10^{21}\right.$ at $\left.\mathrm{cm}^{-3}\right)$ to three coatings $\left(6 \times 10^{21} \mathrm{at} \mathrm{cm}^{-3}\right)$. 


\section{Used Anodes}
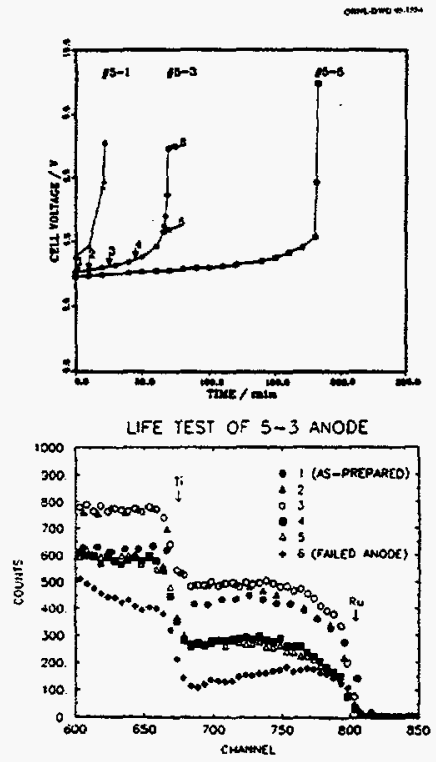

Figure 6(upper): Cell voltage vs. time of electrolysis in a $0.5 \mathrm{M} \mathrm{H}_{2} \mathrm{SO}_{4}$ solution at a constant current of $0.5 \mathrm{~A}$ $\mathrm{cm}^{-2}$ and at $25^{\circ} \mathrm{C}$ for anodes \#5-1, 5-3 \& 5-5; (lower): RBS data ( $2 \mathrm{MeV}$, $160^{\circ}$ scattering angle) of \#5-3 after various times of electrolysis: \#1: 0 ., \#2: 10., \#3: 25., \#4: 45., \#5: 65., and \#6: 77. minutes.
Electrode \#1, prepared with the same procedure as electrode \#5-3, i.e., three successive coatings of 1:5 solution, has been examined by RBS at various times during the course of electrolysis in a $0.5 \mathrm{M} \mathrm{H}_{2} \mathrm{SO}_{4}$ solution at a constant current of $0.5 \mathrm{~A} \mathrm{~cm} \mathrm{~cm}^{-2}$ and at $25^{\circ} \mathrm{C}$. Figure 6 shows, in the upper part, the galvanostatic data of cell potential versus time for electrodes 5-1, 53, 5-5 fabricated with 1, 3 and 5 coats of a 5:1 solution, respectively. Failure of the electrodes happens when the cell potential increases abruptly. The times, at which the fast surge in potential appears, increase with increasing numbers of coats. On the curve for \#5-3 electrode, the voltage/time data before the removing of electrodes \#1 to \#6 for analysis are indicated with the corresponding electrode label. In the lower part of Figure 6 are the Rutherford backscattering spectra of the as-prepared electrode, \#1, together with those of the five electrodes removed after various electrolysis times.

Qualitatively, it appears that with electrodes functioning with a low cell voltage, \#2 and \#3, the spectra are similar to that for the as prepared electrode. Spectra for electrodes \#4 and \#5 show a lower content in ruthenium and are similar. The increase in cell voltage may be related to the decrease in ruthenium content in the electrode. Finally, electrode \#6, which was removed from a cell with excessively high voltage, contains the smallest content of ruthenium. However, it should be noted that all spectra indicate ruthenium and titanium at the electrode surface.

The RBS data have been fitted with the assumption of five sublayers of various Ru:Ti ratios in a $\mathrm{RuO}_{2}-\mathrm{TiO}_{2}$ mixed oxide, and the values of the parameters are reported in Table III. 
TABLE III: RBS analysis of electrode \#5-3 after different times of electrolysis in $0.5 \mathrm{M} \mathrm{H}_{2} \mathrm{SO}_{4}$ at a constant current of $0.5 \mathrm{~A} \mathrm{~cm}^{-2}$ and at $25^{\circ} \mathrm{C}$.

\begin{tabular}{|c|c|c|c|c|}
\hline Electrode & 1 & $2 \& 3$ & $4 \& 5$ & 6 \\
\hline $\begin{array}{l}\text { Numbers of } \\
\text { Layers, } \mathbf{n}\end{array}$ & 5 & 5 & 5 & 5 \\
\hline $\begin{array}{l}\text { Layer } 1 \\
\text { Fluence }\left(\mathrm{at} \mathrm{cm}^{-2}\right) \\
\text { Ru(atom } \\
\text { fraction) } \\
C_{R_{u}}\left(\text { at } \mathrm{cm}^{-3}\right) \\
\end{array}$ & $\begin{array}{c}3.5 \times 10^{17} \\
0.065 \\
5.7 \times 10^{21}\end{array}$ & $\begin{array}{c}2.0 \times 10^{17} \\
0.06 \\
5.3 \times 10^{21}\end{array}$ & $\begin{array}{c}2.2 \times 10^{17} \\
0.035 \\
3.1 \times 10^{21}\end{array}$ & $\begin{array}{c}3.0 \times 10^{17} \\
0.03 \\
2.6 \times 10^{21}\end{array}$ \\
\hline $\begin{array}{l}\text { Layer } 2 \\
\text { Fluence }\left(\text { at } \mathrm{cm}^{-2}\right) \\
\text { Ru(atom } \\
\text { fraction) } \\
C_{\text {Reu }}\left(\text { at } \mathrm{cm}^{-3}\right) \\
\end{array}$ & $\begin{array}{c}5.0 \times 10^{17} \\
0.082 \\
7.5 \times 10^{21}\end{array}$ & $\begin{array}{c}3.0 \times 10^{17} \\
0.085 \\
7.5 \times 10^{21}\end{array}$ & $\begin{array}{c}3.0 \times 10^{17} \\
0.055 \\
4.8 \times 10^{21}\end{array}$ & $\begin{array}{c}3.0 \times 10^{17} \\
0.035 \\
6.2 \times 10^{2}\end{array}$ \\
\hline $\begin{array}{l}\text { Fluence }\left(\mathrm{at} \mathrm{cm}^{-2}\right) \\
\text { Ru(atom } \\
\text { fraction) } \\
C_{R_{u}}\left(\text { at } \mathrm{cm}^{-3}\right) \\
\end{array}$ & $\begin{array}{c}5.0 \times 10^{17} \\
0.085 \\
7.5 \times 10^{21}\end{array}$ & $\begin{array}{c}4.0 \times 10^{17} \\
0.095 \\
8.4 \times 10^{21}\end{array}$ & $\begin{array}{c}4.0 \times 10^{17} \\
0.06 \\
5.3 \times 10^{21}\end{array}$ & $\begin{array}{c}6.0 \times 10^{17} \\
0.04 \\
3.5 \times 10^{21}\end{array}$ \\
\hline $\begin{array}{l}\text { Layer } 4 \\
\text { Fluence (at } \mathrm{cm}^{-2} \text { ) } \\
\text { Ru(atom } \\
\text { fraction) } \\
C_{R_{u}}\left(\text { at } \mathrm{cm}^{-3}\right) \\
\end{array}$ & $\begin{array}{c}2.0 \times 10^{17} \\
0.092 \\
8.2 \times 10^{21}\end{array}$ & $\begin{array}{c}9.0 \times 10^{17} \\
0.1 \\
8.9 \times 10^{21}\end{array}$ & $\begin{array}{l}8.3 \times 10^{17} \\
0.06 \\
5.5 \times 10^{21}\end{array}$ & $\begin{array}{c}1.0 \times 10^{18} \\
0.034 \\
3.0 \times 10^{21}\end{array}$ \\
\hline $\begin{array}{l}\text { Layer } 5 \\
\text { Fiuence (at } \mathrm{cm}^{-2} \text { ) } \\
\text { Ru(atom } \\
\text { fraction) } \\
C_{R_{u}}\left(\text { at } \mathrm{cm}^{-3}\right) \\
\end{array}$ & $\begin{array}{c}2.2 \times 10^{17} \\
0.095 \\
8.4 \times 10^{21}\end{array}$ & $\begin{array}{c}2.4 \times 10^{18} \\
0.110 \\
9.8 \times 10^{21}\end{array}$ & $\begin{array}{c}2.6 \times 10^{18} \\
0.065 \\
5.7 \times 10^{21}\end{array}$ & $\begin{array}{c}2.8 \times 10^{18} \\
0.025 \\
2.2 \times 10^{21}\end{array}$ \\
\hline Thickness $(\dot{A})$ & 4896 & 4712 & 4930 & 5713 \\
\hline
\end{tabular}


Figure 7 summarizes the $\mathrm{Ru}$ concentration profiles in electrodes \#1 to \#6. The results do not show a decreasing thickness of the active layer with

Ru CONCENTRATION PROFILE IN OXIDE

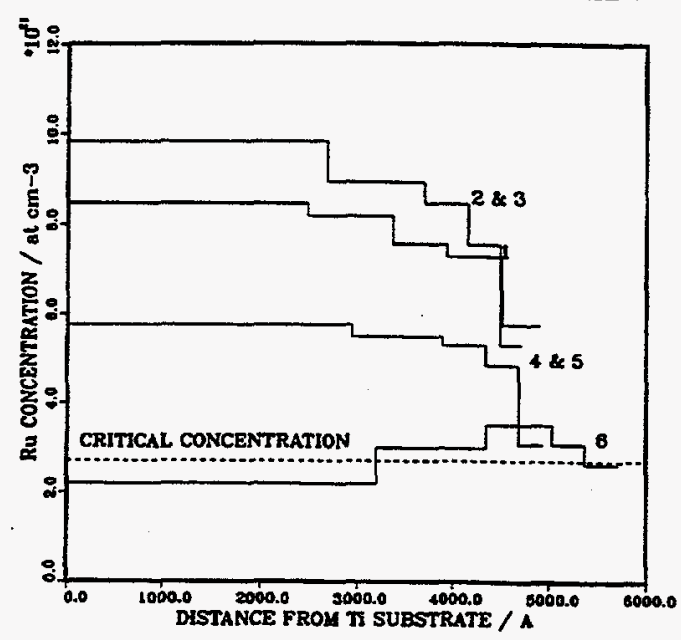

Figure 7 Measured concentration profiles in electrodes \#1 to \#6. The critical concentration value was obtained for the semiconductor/metal transition in anodic oxide of Ru-implanted titanium alloys ${ }^{19}$. use, but clearly show a depletion of $\mathrm{Ru}$ across the whole layer. The data could not be fitted with the assumption of a pure $\mathrm{TiO}_{2}$ layer either at the electrode surface or at the oxide/Ti substrate interface. The deactivation of the electrode is more likely due to the decrease in conductivity of the oxide depleted in conducting $\mathrm{RuO}_{2}$ than to the formation of an insulating pure $\mathrm{TiO}_{2}$ layer. In a related study of anodic oxide films grown on Ruimplanted Ti alloys, electrochemical measurements of Tafel slope and optical absorption measurements by Photoacoustic Spectrometry ${ }^{20}$ concluded to a critical composition of $\mathrm{Ru}$ (IV) in the oxide below which the mixed oxide becomes non-conducting.

The critical concentration, measured for these anodic layers, is indicated in Figure 7 by a dashed horizontal line. The concentration profile in the failed electrode lies below and/or very close to the critical concentration line. Similarly, the ruthenium concentration profile measured by RBS and shown in Figure 5 for electrode \#5-1 has concentrations lower or close to the critical concentration. These values are consistent with the polarization data for electrode \#5-1 shown in Figure 6 where \#5-1 exhibits the highest initial cell voltage and the shortest life time.

Further indication of changes in the conductivity of electrodes \#1 to \#6 have been sought independently by measurements of Tafel slope and by A.C. impedance measurements. Anode polarization data were obtained in $5 \mathrm{M} \mathrm{NaCl}$ solutions at $70^{\circ} \mathrm{C}$ and $\mathrm{pH} \mathrm{3-4}$. The results, shown in Figure 8, indicate a Tafel slope of $38-40 \mathrm{mV}$ per decade for a fresh electrode (\#1); this Tafel slope value is in agreement with the data published in the literature ${ }^{21}$ for $\mathrm{RuO}_{2}-\mathrm{TiO}_{2}$ electrodes, with a $\mathrm{RuO}_{2}$ content of more than $20-30 \mathrm{~mol} \%$, in $\mathrm{NaCl}$ solutions. The Tafel slope remained unchanged for electrodes used as anodes

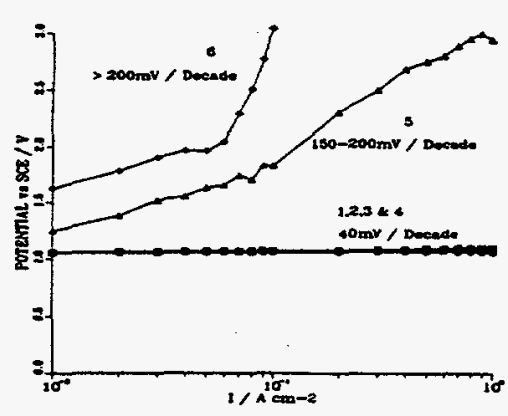

Figure 8 Anodic polarization in $5 \mathrm{M} \mathrm{NaCl}$ at $70^{\circ} \mathrm{C}$ and $\mathrm{pH} 3-$ 4 of electrodes \#1 to \#6 during electrolysis in $\mathrm{H}_{2} \mathrm{SO}_{4}$ solution for up to 45 minutes at a current density of $0.5 \mathrm{~A} \mathrm{~cm}^{-2}$; it suggests that no degradation, detectable by polarization measurements, takes place during the initial period of electrolysis. However, the electrodes after longer times of electrolysis have "Tafel slope" larger than $120 \mathrm{mV} /$ decade and reaching much higher values at longer times (i.e., $>77 \mathrm{~min}$.). The increased value of the slope of the potential / log i curve for used electrodes may point to a change in the reaction mechanism and to the formation of a resistive component during the course of the chlorine evolution reaction. 
The decrease in conductivity, suggested by the polarization data, also is evident in Figure 9 from the A.C. impedance data of the progressively deactivated anode (electrodes \#1 to \#6). The A.C. impedance measurements were carried out in a $5 \mathrm{M} \mathrm{NaCl}$ solution in the non-Faradaic region, where the primary reaction is reported to $\mathrm{be}^{5}$

$$
2 \mathrm{RuO}_{2}+2 \mathrm{H}^{+}+2 \mathrm{e}^{-} \rightarrow \mathrm{Ru}_{2} \mathrm{O}_{3}+\mathrm{H}_{2} \mathrm{O}
$$

Theoretically, reaction (4), at a planar electrode, can be represented by the equivalent circuit (9A). Depending on the magnitude of the exchange current density or charge transfer resistance $\left(R_{v}\right)$, the Nyquist plots present a distinctive semicircle interpreted by a finite $R_{t}$. However, with porous electrodes, the Nyquist plots would exhibit ${ }^{22}$ a phase angle of $45^{\circ}$ at $\omega \rightarrow \infty$ for the reaction scheme noted in equation (4). Thus, the increase in $R_{t}$ suggested by the Tafel slope values, is confirmed by the A.C. impedance data. It should be stated that increased $R_{t}$ can arise from lowered exchange current density and/or increased matrix resistivity. $R_{1}$ and $C_{\phi}$ values were derived from the Nyquist and Bode plots following the simple procedure outlined in Reference 23, and are presented in Table IV together with the Tafel slope values. These results show that, as the electrode is anodically polarized in $\mathrm{H}_{2} \mathrm{SO}_{4}$ solution, the electrode develops significant resistivity, presumably as a result of loss of $\mathrm{Ru}$ sites from the catalyst surface. The loss of $\mathrm{Ru}$ sites is also consistent with a smaller adsorption pseudocapacitance since this capacitive term results from the $\mathrm{RuO}_{2}=\mathrm{Ru}_{2} \mathrm{O}_{3}$ equilibrium. The electrochemical measurements complemented the RBS data in showing that the deactivation of $\mathrm{RuO}_{2}-\mathrm{TiO}_{2}$ thin film electrodes in sulfuric acid solution is a consequence of loss of ruthenium.

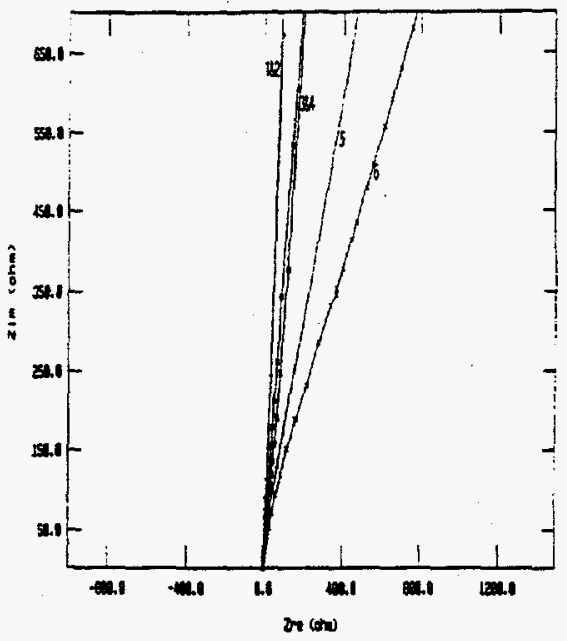

Figure 9 Nyquist plots for electrodes \#1 to \#6 and equivalent circuit for a planar electrode. $R_{s}$ solution resistance, $C_{d}$ double layer capacitance, $R_{t}$ charge transfer resistance, $\mathrm{C}_{\phi}$ adsorption pseudocapacitance.

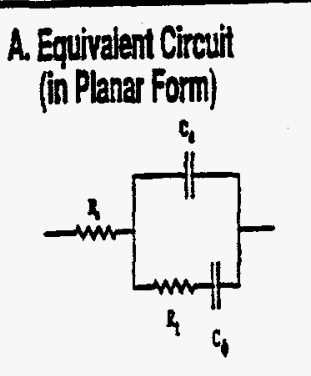


TABLE IV: Summary of data from anodic polarization measurements in $\mathrm{H}_{2} \mathrm{SO}_{4}$ solution and A.C. impedance measurements in $\mathrm{NaCl}$ solution

\begin{tabular}{|c|c|c|c|}
\hline $\begin{array}{c}\text { Time of } \\
\text { Electrolysis } \\
\text { minute }\end{array}$ & $\begin{array}{c}\text { Tafel slope } \\
\mathrm{mV}\end{array}$ & $\begin{array}{c}\mathrm{C} \phi \\
\mathrm{mF} \mathrm{cm}\end{array}$ & $\begin{array}{c}\mathbf{R}_{\mathrm{t}} \\
\mathrm{cm}^{-2}\end{array}$ \\
\hline 0. & 40 & 5.6 & 0 \\
\hline 10. & 40 & 5.6 & 0 \\
\hline 25. & 40 & 5.6 & 0 \\
\hline 45. & 40 & 2.5 & 0 \\
\hline 65. & $150-200$ & 0.56 & \\
\hline 77. & 7200 & 0.08 & 3 \\
\hline
\end{tabular}

\section{SUMMARY}

The deactivation of $\mathrm{RuO}_{2}-\mathrm{TiO}_{2}$ DSA electrodes is readily observable from study of the electrode performance in the production of chlorine. The failure of the electrodes happens with little or no progressive decrease in the electrode performance; and accordingly electrochemical measurements, such as Tafel slope, A.C. impedance measurements, point to an abrupt decrease in electrode conductivity. In this study, Rutherford Backscattering Spectrometry has been successful in measuring the ruthenium concentration profile in electrodes at different times of use. The decrease in electrode activity has been linked conclusively to a decrease in the ruthenium content of the electrode. The measured profiles demonstrate that the loss of Ru takes place across the $(-5000 \AA)$ thin coating, and that failure occurs before the complete depletion of ruthenium and without the formation of a pure $\mathrm{TiO}_{2}$ layer. Concentrations on the order of 2.7-3. $10^{21} \mathrm{Ru}$ at $\mathrm{cm}^{-3}$ in the mixed dioxide are insufficient to sustain the chlorine current. This result quantitatively agrees with the critical composition of $2.710^{21} \mathrm{Ru}$ at cm${ }^{-3}$ determined ${ }^{20}$ for the metal/semiconductor transition in $\mathrm{RuO}_{2}-\mathrm{TiO}_{2}$ anodic oxides of $\mathrm{Ru}$, Ti alloy films produced by ion-implantation of $\mathrm{Ru}$ into titanium.

\section{REFERENCES}

1. L. Calvert Curlin, Tilak V. Bommaraju and Constance B. Hansson, in KirkOthmer-Encyclopedia of Chemical Technology, Fourth Ed. Volume $\mathrm{N}^{\circ} 1$, John Wiley \& Sons, Inc., 1991, p.938.

2. V. de Nora and J.W. Kuhn Von Burgsdorff, Chem. Ing. Tech. 47, 125 (1975).

3. H.B. Beer, J. Electrochem. Soc., 127, 303C (1980); Neth. Pat. Appl., 6,606,302 (1966). 
4. E.J. Kelly, D.E. Heatherly, C.E. Vallet and C.W. White, J. Electrochem. Soc., 134, 1667 (1987).

5. S. Trasatti, Electrochim. Acta, 36, 225 (1991).

6. S. Pizzini, G. Buzzanca, C. Mari, L. Rossi and S. Torchio, Mater. Res. Bull., 7, 449 (1972).

7. I.M. Kodintsev, S. Trasatti, M. Rubel, A. Wieckowski and N. Kaufher, Langmuir, 8, 283 (1992).

8. Lj. Atanasoska, R. Atanasoski and S. Trasatti, Vacuum, 40, 91 (1990).

9. C.E. Vallet, A. Choudhury, P.E. Sobol and C.W. White, Electrochim. Acta, 38, 1313 (1993).

10. A. de Battesti, G. Lodi and M. Cappadonia, J. Electrochem. Soc., 136, 2596 (1989).

11. C. Angelinetta, S. Trasatti, Lj.D. Atanasoska and R.T. Atanasoski, J. Electroanal. Chem. Interfacial Electrochem., 214, 535 (1986).

12. R. Kotz, H.J. Lewerenz, P. Bruesch and S. Stucki, J. Electroanal. Chem., 150, 209 (1983).

13. J. Augustinski, L. Balsenc and J. Hinden, J. Electrochem. Soc., 125, 1093 (1978).

14. Lj. Atanasoska, R.T. Atanasoski, F.H. Pollak and W.E. O'Grady, Surf. Sci., 230, 95 (1990).

15. K. Kameyama, K. Tsukado, K. Yahikosawa and Y. Takasu, J. Electrochem. Soc., 140, 966 (1993).

16. "Backscattering Spectrometry", Wei-Kan Chu, J.W. Mayer and Marc-A. Nicolet, Academic Press, New York, 1978, p.137.

17. J.P. Biersack and L.G. Haggmark, Nucl. Inst. Meth.,174, 257 (1980).

18. M. Rubel, R. Haasch, P. Mrozek, A. Wieckowski, C. De Pauli and S.Trasatti, Vacuum, 45, 423 (1994).

19. E.P. Bertin, in "X-Ray Spectrometric Analysis: Principles, Instrumentation, Practice, and Applications", Short-Course on X-Ray Spectrometry, Department of Physics, State University of New York at Albany, NY (June 1985). 
20. C.E. Vallet, D.E. Heatherly and C.W. White, J. Electrochem. Soc.,137, 579 (1990).

21. B.V. Tilak and B.E. Conway, Electrochim. Acta, 37, 51 (1992).

INVENTIONS

No invention was made.

\section{COMMERCIALIZATION POSSIBILITIES}

None

\section{PLANS FOR FUTURE COLLABORATION} Corporation.

No plan for further collaboration has been currently initiated by Occidental Chemical

\section{CONCLUSIONS}

The use of Rutherford Backscattering Spectrometry, in connection with the electrochemical science, is currently not very extensive. However, with the growing interest of electrochemists in experimenting with the wide variety of surface analysis techniques, RBS should not be disregarded because of the cost of the technique.

This study demonstrates the advantages of Rutherford Backscattering Spectrometry (RBS) for characterizing "real life" electrodes. Theses advantages come from the use of

- nondestructive method

- quantitative method with no need for standards

- method which gives data at the surface and near surface (a few thousands $\AA$ ). The latter possibility allows a nondestructive depth profiling of the active region of an electrode. This is particularly advantageous for the study of porous oxides with electrocatalytic properties for various important reactions. The characterization by RBS could serve as a control during the multi step fabrication of the mixed oxide electrodes and help in identifying the best 
conditions for building a mixed oxide layer of high electroactive activity and long use.

This study demonstrates that the life time of the actual $\mathrm{RuO}_{2}-\mathrm{TiO}_{2}$ electrodes is limited by the loss of $\mathrm{RuO}_{2}$ over a region of at least $5000 \AA$ thick leading to a blocking electrode. Since, the failed electrodes retained some ruthenium at the surface and near the surface, it may be possible to use the remaining potential activity by modifying the electrode for increasing its electrical conductivity.

\title{
DISTRIBUTION LIST
}

\author{
B.R. Appleton \\ C.E. Bamberger \\ D.B. Beach \\ G.M. Brown \\ R.T. Chung \\ J. E. Ferguson
}

Pamela L. Gorman

Steve Hamel, DOE Patent Counsel

R.D. Kelley, DOE Headquarters Basic Energy Sciences

L. Maya

R.E. Mesmer

OSTI, DOE Office of Scientific and Technical Information

W.P. Painter

M. Paranthaman

M.L. Poutsma

D.B. Poker

C.G. Rader, Occidental Chemical Corporation

J.B. Roberto

STIO, Site Technical Information Office

B.V. Tilak, Occidental Chemical Corporation

C.E. Vallet

C.W. White

D.M. Zehner

R.A. Zuhr 


\section{Final Report Certification \\ for \\ CRADA Number ORNL95-0331 \\ between \\ Lockheed Martin Energy Research Corporation \\ and}

Occidental Chemical Corporation

The following certification is made for the subject final report:

- 1a) The final report contains a claim that information contained in the final report is

qualifying as "Protected CRADA Information" (PCI) and any PCI is identified as such in the report;

or

X lb) neither Energy Research nor the participant asserts any claim to information

contained in the final report as qualifying as "Protected CRADA Information";

2) that Energy Research and the participant has no objection to public distribution of the final report due to patentable information, and

3) the final report contains no proprietary information

For the Participant:

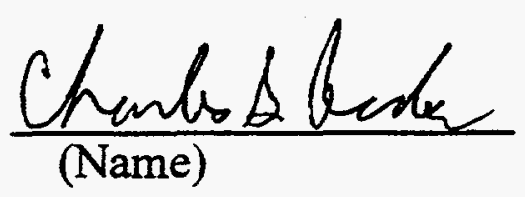

Vice President

Technology \& Development

(Title)

May 13, 1996

(Date) 